OPEN ACCESS

Edited by:

Salman Razvi,

Newcastle University, United Kingdom

Reviewed by: Tamer Mohamed Elsherbiny,

Alexandria University, Egypt

Poupak Fallahi,

University of Pisa, Italy

${ }^{*}$ Correspondence:

Shengfeng Wang

shengfeng1984@126.com

Yongfeng Song

syf198506@163.com

Yi Ning

ningyi@vip.163.com

Liming $L$

Imlee@bjmu.edu.cn

${ }^{\dagger}$ These authors have contributed equally to this work and

share first authorship

Specialty section:

This article was submitted to

Thyroid Endocrinology,

a section of the journal

Frontiers in Endocrinology

Received: 05 August 2021 Accepted: 22 November 2021 Published: 13 December 2021

Citation:

Zhang $Y$, Wang $K$, Qin W, Jin C, Song $Y$, Jia $P$, Wang $S$, Song $Y$, Ning $Y$ and Li L (2021) Six Air Pollutants Associated With Increased Risk of

Thyroid Nodules: A Study of

4.9 Million Chinese Adults.

Front. Endocrinol. 12:753607. doi: 10.3389/fendo.2021.753607

\section{Six Air Pollutants Associated With Increased Risk of Thyroid Nodules: A Study of 4.9 Million Chinese Adults}

\author{
Yunjing Zhang ${ }^{1 \dagger}$, Kai Wang ${ }^{2,3,4 \dagger}$, Wei Qin ${ }^{5}$, Cheng Jin ${ }^{6,7}$, Yiqing Song ${ }^{8}$, Peng Jia ${ }^{9,10}$, \\ Shengfeng Wang ${ }^{1 *}$, Yongfeng Song ${ }^{2,3,4^{*}}$, Yi Ning ${ }^{6,7^{*}}$ and Liming $\mathrm{Li}^{1 *}$ \\ 1 Department of Epidemiology and Biostatistics, School of Public Health, Peking University Health Science Center (PKUHSC), \\ Beijing, China, ${ }^{2}$ Department of Endocrinology, Shandong Provincial Hospital Affiliated to Shandong First Medical University, \\ Jinan, China, ${ }^{3}$ Shandong Clinical Medical Center of Endocrinology and Metabolism, Jinan, China, ${ }^{4}$ Institute of Endocrinology \\ and Metabolism, Shandong Academy of Clinical Medicine, Jinan, China, ${ }^{5}$ Department of Social Medicine and Health \\ Education, School of Public Health, PKUHSC, Beijing, China, ${ }^{6}$ Meinian Institute of Health, Beijing, China, ${ }^{7}$ PKUHSC Meinian \\ Public Health Research Institute, Beijing, China, ${ }^{8}$ Department of Epidemiology, Richard M. Fairbanks School of Public Health, \\ Indiana University, Indianapolis, IN, United States, ${ }^{9}$ School of Resources and Environmental Science, Wuhan University, \\ Wuhan, China, ${ }^{10}$ International Institute of Spatial Lifecourse Epidemiology (ISLE), Wuhan University, Wuhan, China
}

Background: Thyroid nodules has become a significant public health issue worldwide with a rapidly increasing prevalence. However, its association with outdoor air pollution remains poorly understood. We aim to investigate the relationship between six outdoor air pollutants $\left(\mathrm{PM}_{2.5}, \mathrm{PM}_{10}, \mathrm{NO}_{2}, \mathrm{SO}_{2}, \mathrm{CO}\right.$, and $\left.\mathrm{O}_{3}\right)$ and the risk of thyroid nodules.

Methods: We utilized a database including 4,920,536 participants who attended the annual physical examinations in the Meinian HealthCare Screening Center in 157 Chinese cities in 2017. City-specific concentrations of six pollutants $\left(\mathrm{PM}_{2.5}, \mathrm{PM}_{10}, \mathrm{NO}_{2}, \mathrm{SO}_{2}, \mathrm{CO}\right.$, and $\mathrm{O}_{3}$ ) from 2015 to 2017 were estimated based on the China's National Urban Air Quality Real Time Publishing Platform. Thyroid nodule was measured with ultrasound. Multivariable Logistic regression was used to examine the associations between air pollutants and thyroid nodules with adjustment for age, sex, education, smoking, body mass index, fasting blood glucose, triglyceride, low density lipoprotein cholesterol, high density lipoprotein cholesterol, urine iodine, gross domestic product, and thyroid stimulating hormone. We conducted stratified analyses to investigate potential effect modification by sex, age, and urine iodine groups.

Results: Approximately $38 \%$ of the participants $(1,869,742)$ were diagnosed with thyroid nodules. Each of the six air pollutants was significantly and linearly associated with the risk for thyroid nodules. The adjusted odds ratios [95\% Cl] for every increase of $10 \mu \mathrm{g} / \mathrm{m}^{3}$ for $\mathrm{PM}_{2.5}, \mathrm{PM}_{10}, \mathrm{NO}_{2}, \mathrm{SO}_{2}$, and $\mathrm{O}_{3}$ were 1.062 [1.061, 1.064], 1.04 [1.03, 1.04], 1.10 [1.09, $1.10], 1.11$ [1.11, 1.12], and 1.151 [1.149, 1.154], respectively; The odds ratio for each 
increase of $1 \mathrm{mg} / \mathrm{m}^{3}$ for $\mathrm{CO}$ was 1.50 [1.49 to 1.52]. Furthermore, these associations were significantly higher in the participants who were men, younger, or having lower urine iodine level $(p<0.001)$.

Conclusion: The six air pollutants may contribute to the high prevalence of thyroid nodules in China.

Keywords: thyroid nodules, $\mathrm{PM}_{2.5}, \mathrm{PM}_{10}, \mathrm{NO}_{2}, \mathrm{SO}_{2}, \mathrm{CO}, \mathrm{O}_{3}$, dose-response relationship

\section{INTRODUCTION}

Thyroid nodules (TNs) are highly prevalent worldwide with 4 to $7 \%$ by physical examinations and 30 to $67 \%$ by imaging studies (1). Although most nodules are benign, up to $20 \%$ have been found to be malignant on excision (2). Increased diagnosis of TNs may be partly due to the advancements in diagnostic technologies, especially high resolution ultrasonography, but the worldwide increase of TNs may be due to multiple factors (2), including a list of individual-level risk factors (3-5), such as sex, age, iodine intake, obesity, diabetes, dyslipidemia, and thyroid autoimmunity. Air pollution may play a significant role in the development of TNs.

Air pollutants, especially particulate matters in outdoor air pollution, are well-known human carcinogens and are increasingly associated with adverse effects on the thyroid, including disturbance of thyroid function (6-9). For example, one study with 433 pregnant women reported an inverse association between maternal exposure to $\mathrm{PM}_{2.5}$ and the maternal free thyroxine (FT4) levels (6); airborne particulate matter (APM), has significantly affected thyroxine binding to transthyretin (TTR) and the reduction of thyroxine (T4) level (10). Understanding the association of air pollutants and the risk of TNs has particularly important public health implications for disease prevention. Existing studies have been focused on evaluating the associations between air pollutants and thyroid dysfunction, however, in a relatively limited sample (6-9). Moreover, most participants with TNs presented morphological changes but were rarely hypothyroid/thyrotoxic (11). To the best of our knowledge, no human studies have examined the associations between major air pollutants and TNs.

Therefore, this study aimed to investigate the associations between exposure to six major air pollutants $\left(\mathrm{PM}_{2.5}, \mathrm{PM}_{10}, \mathrm{NO}_{2}\right.$, $\mathrm{SO}_{2}, \mathrm{CO}$, and $\mathrm{O}_{3}$ ) and the prevalent risk of thyroid nodules in a large health check-up population. This study has particularly important public health implications for TN prevention and air pollution control policies in all countries with serious air pollution issues and challenges.

\section{METHODS}

\section{Database and Study Population}

The Meinian HealthCare Screening Center is a private membership chain clinic with 319 health screening centers (Figure 1) covering nearly all geographic regions in mainland China (157 cities), which provides periodic health examinations to its members, mostly one yearly examination for each person.
For those who attended two screenings or more, results from the most recent checkup were included, to ensure the independency of data. Every participant had signed a consent form that authorizes the Meinian Health Screening Centers to analyze the data generated from the medical screenings for academic and policy purposes. The study used the database generated from the medical screenings instead of collecting new data for the sake of the study.

The analysis was restricted to adults aged 18 years and over. A total of 4,920,536 individuals in 2017 were kept in the study without missing the value of key variables, namely, age, sex, fasting plasma glucose (FPG), body mass index (BMI), triglyceride (TG), low density lipoprotein cholesterol (LDL-C), and high density lipoprotein cholesterol (HDL-C). Data related to individual identification were removed and everyone remained anonymous during the entire study process. The project was approved by the Ethical Committee of the Health Science Center of Peking University (IRB00001052-19077).

\section{Measures of TNs}

Ultrasound examination of the thyroid nodules was performed routinely and evaluated independently by the two senior experts with Affiniti 50 ultrasound system (Philips, Germany), which was approved by the National Center for Medical Device Evaluation (CMDE). Scans of both thyroid lobes and isthmus were obtained in both transverse and longitudinal planes. The following features were measured for each nodule: size, margin, shape, aspect ratio, capsule, hypoechoic halo, internal composition, echogenicity, presence of calcifications, vascularity on color Doppler, and cervical lymph node status.

\section{Measures of Air Pollutant Concentration}

The average city-level annual concentrations of six air pollutants $\left(\mathrm{PM}_{2.5}, \mathrm{PM}_{10}, \mathrm{NO}_{2}, \mathrm{SO}_{2}, \mathrm{CO}\right.$, and $\left.\mathrm{O}_{3}\right)$ for 2015-2017 in this study were calculated based on hourly data from the China's National Urban Air Quality Real Time Publishing Platform. The data collection and processing followed ambient air quality standards (GB 3095-2012) and the Chinese Technical Regulation for Ambient Qir Quality Assessment (HJ 663-2013). The detail methodology has been described previously $(12,13)$.

\section{Covariates}

Participants were asked to provide their personal information for health history, demographic information, and medical information during the examination. BMI was calculated as weight in kilograms divided by the square of height in meters. Blood samples were drawn by venipuncture after $8-12 \mathrm{~h}$ of overnight fasting to measure 


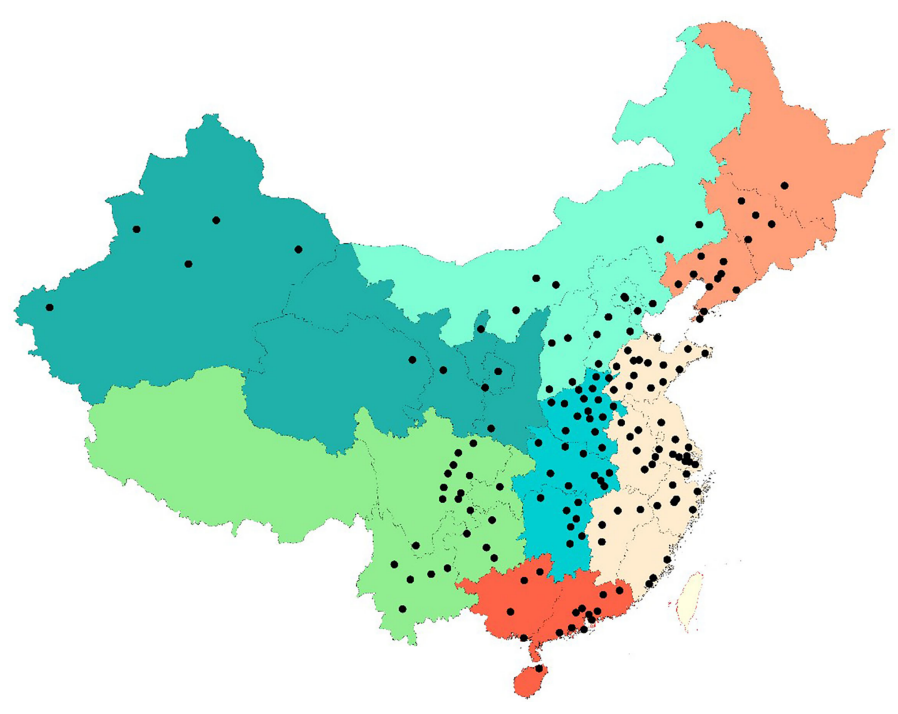

FIGURE 1 | Map of participating HealthCare Screening Centers included into the analysis.

FPG, HDL-C, LDL-C, TG, and thyroid function indexes (thyroglobulin antibodies [anti-TG], thyroid peroxidase antibody [anti-TPO], total triiodothyronine [TT3], total thyroxine [TT4], and thyroid stimulating hormone [TSH]). Serum cholesterol and triglycerides were assessed enzymatically with commercially available reagents at the clinical biochemical laboratories in each center (Roche E601, Germany). Thyroid TSH, TT3, TT4, anti-TG, and anti-TPO were measured using electrochemical luminescence method (Roche E601, Germany). FPG was grouped into three subgroups: $\leq 6.1 \mathrm{mmol} / \mathrm{l}, 6.1-6.9 \mathrm{mmol} / \mathrm{l}$, and $\geq 7.0 \mathrm{mmol} / \mathrm{l}$. BMI was divided into three levels: $<24 \mathrm{~kg} / \mathrm{m}^{2}, 24-27.9 \mathrm{~kg} / \mathrm{m}^{2}$, and $\geq 28 \mathrm{~kg} /$ $\mathrm{m}^{2}$ according to the Chinese guidelines for prevention and control of overweight and obesity (14). Serum TG, HDL-C, and LDL-C levels were classified on the basis of the Third Report of the Expert Panel on Detection, Evaluation, and Treatment of High Blood Cholesterol in Adults. The cut points for anti-TG, anti-TPO were $115 \mathrm{IU} / \mathrm{ml}$, and $34 \mathrm{IU} / \mathrm{ml}$, respectively.

Data about the gross domestic product per capita (GDP) and average years of education were collected from the China Statistical Yearbook for 2017. Average smoking rates were extracted from Wang et al. (15), which were estimated based on national cross-sectional surveys in 2013. The average urine iodine for each province was obtained from personal communication (TIDE program conducted by the Chinese Society of Endocrinology), which was a large-scale populationbased nationwide epidemiological survey of iodine nutrition status and thyroid disease covering 31 provinces and 78,470 individuals (16).

\section{Statistical Analyses}

The primary outcome of interest was the prevalence of thyroid nodules. Continuous variables were described as the mean \pm standard deviation or median (25th-75th percentiles).
The differences between participants with or without thyroid nodules were examined by $t$-tests for normally distributed data or by the Wilcoxon signed rank tests for non-normally distributed data. Categorical variables were presented as numbers and percentages, and intergroup comparisons were analyzed using Chi-square tests.

The analysis specified four logistic regression models as a priori to evaluate the association of thyroid nodules with air pollutants, with adjustments for an increasing number of potential confounders. The confounders were selected through careful consideration of the underlying web of causation based on the priori knowledge $(3-5,17)$, the availability of data in the dataset, and the univariate analysis. Model 1 included only age and sex; Model 2 added individual level variables: FPG, BMI, TG, LDL-C, and HDL-C; Model 3 added city-level variables, namely, GDP, and $\mathrm{O}_{3}$ concentration; and Model 4 added province-level variables: average urine iodine level, average years of education, and average smoking rate. Each air pollutant was analyzed by continuous variables, and also categorical variables divided according to the WHO air quality guideline (AQG) and data distribution of the study (18).

Stratified analyses were conducted to investigate potential effect modification by pre-specified variables: sex, age $(<40,40$ $59,60-79$, or $\geq 80$ years), and urine iodine levels groups (100-199 ug/L and $200 \mathrm{ug} / \mathrm{L}$ ) (19). The Bonferroni correction (nominal $P$ value divided by the number of tests), about 0.0028 for 18 tests (six pollutants $*$ three group variables), would minimize falsepositive error. In sensitivity analyses, city level, TSH, and temperature were added into Model 4 to adjust their potential effect, respectively. Extended confounder models were used in sensitivity analyses because some potential effects of air pollution might be mediated by these factors (TT3 and TT4). Meanwhile, TPOAb and TGAb are two important thyroid autoantibodies, 
which are commonly found in patients with thyroid diseases, and have been confirmed to be two important thyroid autoantibodies to assess the risk of thyroid nodules. In order to further exclude the effect of anti-TG and anti-TPO, subgroup analysis was conducted to restrict the comparison between participants with positive in both indexes and participant with negative in both indexes.

A natural cubic spline model was utilized to study the association between each pollutant and thyroid nodules. In addition, threshold analyses were done by consecutively including participants who had exposure estimates below prespecified thresholds in the analyses, to detect the potential minimum effective concentration for each pollutant using the method described in the study of Beelen et al. (20).

All tests were two-sided and P-values less than 0.05 were judged to be significant (except the stratified analyses). All data analyses were done in SAS 9.4 (SAS Institute Inc., Cary, NC, USA).

\section{RESULTS}

\section{Characteristics of Participants}

The total study population consisted of 4,920,536 participants, of whom $1,869,742$ (38.0\%) were diagnosed with thyroid nodules. The individuals with thyroid nodules were more likely to be female and elderly, and had worse general health status (Table 1). Participants with thyroid nodules presented a lower positive rate for anti-TG and anti-TPO, had a lower level of urine iodine, but had relatively higher pollutant concentrations. Concentrations of air pollutants were varied among different cities, and the minimum number of $\mathrm{PM}_{2.5}$ and $\mathrm{PM}_{10}$ already surpassed the WHO AQG. The correlations of five air pollutants were statistically significant $(P<0.01)$, except for $\mathrm{O}_{3}(P>0.05) . \mathrm{PM}_{2.5}$ was highly correlated with $\mathrm{PM}_{10}(\mathrm{r}=0.90)$ and strongly related with $\mathrm{NO}_{2}(\mathrm{r}=0.64)$ and $\mathrm{CO}(\mathrm{r}=0.61)$. CO had strong correlation with $\mathrm{PM}_{10}(\mathrm{r}=0.61)$ and $\mathrm{SO}_{2}(\mathrm{r}=0.63)$ (Supplementary Table 1).

\section{Association Between Air Pollutants and Thyroid Nodules}

An elevated risk was detected for exposures to any of six air pollutants in all four models (Table 2), with significantly adjusted ORs for each increase of $10 \mu \mathrm{g} / \mathrm{m}^{3} \mathrm{PM}_{2.5}(1.062,95 \%$ confidence interval [CI]: 1.061-1.064), $\mathrm{PM}_{10}(1.04,95 \% \mathrm{CI}: 1.03-$ $1.04), \mathrm{NO}_{2}(1.10,95 \% \mathrm{CI}: 1.09-1.10), \mathrm{SO}_{2}$ (1.11, 95\% CI: $1.11-$ 1.12), $\mathrm{O}_{3}$ (1.151, 95\% CI: 1.149-1.154), and for each increase of 1 $\mathrm{mg} / \mathrm{m}^{3} \mathrm{CO}(1.50,95 \% \mathrm{CI}: 1.49-1.52)$ in full adjusted model. All of the six pollutants also presented the statistically significant linear trends $(P$-value $<0.0001)$. Estimates for the five types of pollutants in two-pollutant models adjusted for $\mathrm{O}_{3}$ (because of its weak correlation with other pollutants) did not alter the association significantly, compared to the single-pollutant models (Table 2). Stratified analysis indicated that ORs were relatively lower in participants who were women and elderly, and also in those having higher urine iodine level (Figure 2). The significant positive associations for $\mathrm{PM}_{2.5}, \mathrm{PM}_{10}, \mathrm{NO}_{2}$, and $\mathrm{CO}$ were observed for participants with low urine iodine levels, but all ORs turned to be not significant within those with high iodine levels.

\section{Sensitivity Analyses}

Only $25.0 \%$ of participants have tested TSH, and the additional adjustment for either TSH or TSH together with atmospheric temperature did not significantly change ORs compared to those for the main model, with only a small further decrease in the magnitude of ORs (Table 3).

Only $1.0 \%$ of participants had available thyroid autoantibody results (Supplementary Table 3). Analyses restricted to participants with anti-TG $(+)$ and anti-TPO $(+)$ and those with anti-TG (-) and anti-TPO (-) resulted in the slightly smaller ORs for all pollutants than the ORs from the main analyses including all participants. Most of the ORs turned to be not significant, except for $\mathrm{CO}$ and $\mathrm{O}_{3}$. ORs were both significantly larger for $\mathrm{CO}(2.27,95 \% \mathrm{CI}: 2.10-2.46)$ and $\mathrm{O}_{3}(1.38,95 \% \mathrm{CI}$ : $1.36-1.42)$ in anti-TG (-) and anti-TPO (-) groups (Supplementary Table 2).

\section{Threshold Analyses and Nonlinear Tests for Air Pollutants}

In the threshold analyses, ORs for TN increased significantly when people were exposed to $\mathrm{NO}_{2}$ concentration of below $25 \mu \mathrm{g} / \mathrm{m}^{3}$, while ORs for TN kept rising significantly when only including participants exposed to the $\mathrm{NO}_{2}$ concentration of below $0.70 \mathrm{mg} /$ $\mathrm{m}^{3}$. The ORs for TN were not significant when participants within either $\mathrm{SO}_{2}$ less than $10 \mu \mathrm{g} / \mathrm{m}^{3}$ or $\mathrm{O}_{3}$ less than $50 \mu \mathrm{g} / \mathrm{m}^{3}$ were restricted. These findings were complemented by the results of the spline models, which showed that the association did not deviate significantly from a linear association (Figure 3). Any rise in each of the air pollutant exposure was associated with an elevated thyroid nodules risk.

\section{DISCUSSION}

As mentioned before, there has been no prior study that has extensively discussed the potential risk that outdoor air pollutants have on the increasing prevalence of TNs. This study found that each of the six major air pollutants $\left(\mathrm{PM}_{2.5}, \mathrm{PM}_{10}, \mathrm{NO}_{2}, \mathrm{SO}_{2}, \mathrm{CO}\right.$, and $\mathrm{O}_{3}$ ) were statistically associated with an increased risk of TNs among about 4.9 million Chinese adults. These associations were significantly stronger in the participants, who were men, younger, and also having lower urine iodine level. Those associations were close to linear in all and subgroup analyses, indicating that air pollutants exposure was associated with an elevated TNs risk without minimum effective concentrations.

The association between major air pollutants and TNs was near linear without minimum effect concentrations. The linear results for $\mathrm{PM}_{2.5}$ and $\mathrm{PM}_{10}$ were indeed unsurprising because the minimum levels for both the two pollutants in this study exceeded the level (minimum $10 \mu \mathrm{g} / \mathrm{m}^{3}$ vs. $20 \mu \mathrm{g} / \mathrm{m}^{3}$ ) suggested by the WHO air quality guideline (18). However, it was unexpected for $\mathrm{NO}_{2}, \mathrm{SO}_{2}, \mathrm{CO}, \mathrm{O}_{3}$, and ORs to remain statistically significantly heightened when only participants with concentrations far below corresponding the WHO air quality 
TABLE 1 | Comparison of basic characteristics between individuals with different thyroid nodules status $(N=4,920,536)$.

\begin{tabular}{|c|c|c|c|}
\hline Characteristics & With thyroid nodules ${ }^{a}$ & Without thyroid nodules ${ }^{a}$ & $P$-value \\
\hline $\mathrm{N}$ & $1,869,742(38.00)$ & $3,050,794(62.00)$ & - \\
\hline Male & $803,102(42.95)$ & $1,795,807$ (58.86) & $<0.0001$ \\
\hline Age (yrs) & $48(37,57)$ & $37(30,48)$ & $<0.0001$ \\
\hline City scale & & & $<0.0001$ \\
\hline Big city & 869,747 (46.52) & 1,502,032 (49.23) & \\
\hline Small-medium city & $981,922(52.52)$ & $1,509,690(49.49)$ & \\
\hline County & $18,073(0.97)$ & $39,072(1.28)$ & \\
\hline History of hypertension ${ }^{\mathrm{b}}$ & $196,437(12.44)$ & $156,471(6.07)$ & $<0.0001$ \\
\hline Treatment of hypertension ${ }^{b}$ & $159,529(10.10)$ & $112,694(4.37)$ & $<0.0001$ \\
\hline Systolic pressure $(\mathrm{mmHg})^{\mathrm{C}}$ & $124(112,139)$ & $120(110,131)$ & $<0.0001$ \\
\hline Diastolic pressure $(\mathrm{mmHg})^{\mathrm{c}}$ & $76(68,84)$ & $74(66,82)$ & $<0.0001$ \\
\hline History of diabetes ${ }^{b}$ & $68,497(4.34)$ & $50,958(1.98)$ & $<0.0001$ \\
\hline Treatment of diabetes $^{b}$ & $51,693(3.27)$ & $35,571(1.38)$ & $<0.0001$ \\
\hline Fasting plasma glucose (mmol/L) & & & $<0.0001$ \\
\hline$\leq 6.1$ & $1,639,756(87.70)$ & $2,825,449(92.61)$ & \\
\hline $6.1-7.0$ & $111,583(5.97)$ & $115,824(3.80)$ & \\
\hline$\geq 7.0$ & $118,403(6.33)$ & $109,521(3.59)$ & \\
\hline Body mass index $\left(\mathrm{kg} / \mathrm{m}^{2}\right)$ & & & $<0.0001$ \\
\hline$<24$ & 860,069 (46.00) & $1,607,737(52.70)$ & \\
\hline $24.0-27.9$ & $720,084(38.51)$ & $1,043,207(34.19)$ & \\
\hline$\geq 28.0$ & 289,589 (15.49) & $399,850(13.11)$ & \\
\hline History of dyslipidemia ${ }^{\mathrm{b}}$ & $25,201(1.60)$ & $30,095(1.17)$ & $<0.0001$ \\
\hline Triglyceride (mmol/L) & & & $<0.0001$ \\
\hline$<1.7$ & $1,305,479(69.82)$ & $2,173,381(71.24)$ & \\
\hline$\geq 1.7$ & $564,263(30.18)$ & $877,413(28.76)$ & \\
\hline High-density lipoprotein (mmol/L) & & & $<0.0001$ \\
\hline$<1.03$ & 238,922 (12.78) & $428,941(14.06)$ & \\
\hline $1.03-1.56$ & $1,138,778(60.91)$ & $1,886,320(61.83)$ & \\
\hline$\geq 1.56$ & $492,042(26.32)$ & $735,533(24.11)$ & \\
\hline Low Density lipoprotein (mmol/L) & & & $<0.0001$ \\
\hline$<2.59$ & $824,510(44.10)$ & $1,486,716(48.73)$ & \\
\hline $2.59-3.35$ & $637,041(34.07)$ & $1,007,338(33.02)$ & \\
\hline $3.36-4.13$ & $299,364(16.01)$ & 416,176 (13.64) & \\
\hline $4.14-4.90$ & $84,893(4.54)$ & $109,003(3.57)$ & \\
\hline$\geq 4.91$ & $23,934(1.28)$ & $31,561(1.03)$ & \\
\hline Total cholesterol (mmol/L) $)^{\mathrm{C}}$ & $4.86(4.25,5.54)$ & $4.70(4.12,5.36)$ & $<0.0001$ \\
\hline Thyroglobulin antibodies $(+)^{d}$ & $8,867(14.35)$ & $8,436(18.16)$ & $<0.0001$ \\
\hline Anti-thyroid peroxidase antibody $(+)^{d}$ & $6,497(17.78)$ & $5,834(20.97)$ & $<0.0001$ \\
\hline Total triiodothyronine $(\mathrm{umol} / \mathrm{l})^{\mathrm{d}}$ & $1.5(1.3,1.8)$ & $1.5(1.3,1.8)$ & $<0.0001$ \\
\hline Total tetraiodothyronine (umol/l) $)^{d}$ & $92.9(75.7,109.3)$ & $91.2(74.7,107.3)$ & $<0.0001$ \\
\hline Thyroid Stimulating Hormone (mlU/L) $)^{d}$ & $1.8(1.1,2.9)$ & $1.8(1.1,2.8)$ & $<0.0001$ \\
\hline $\mathrm{PM}_{2.5}\left(\mathrm{ug} / \mathrm{m}^{3}\right)$ & $52.4(40.7,66.6)$ & $50.1(39.5,62.2)$ & $<0.0001$ \\
\hline $\mathrm{PM}_{10}\left(\mathrm{ug} / \mathrm{m}^{3}\right)$ & $88.4(69.2,113.8)$ & $86.2(65.0,99.7)$ & $<0.0001$ \\
\hline $\mathrm{NO}_{2}\left(\mathrm{ug} / \mathrm{m}^{3}\right)$ & $41.7(31.6,45.7)$ & $41.7(31.4,46.4)$ & $<0.0001$ \\
\hline $\mathrm{SO}_{2}\left(\mathrm{ug} / \mathrm{m}^{3}\right)$ & $19.0(13.7,29.3)$ & $15.9(13.1,24.7)$ & $<0.0001$ \\
\hline $\mathrm{CO}\left(\mathrm{mg} / \mathrm{m}^{3}\right)$ & $0.98(0.85,1.27)$ & $0.97(0.83,1.24)$ & $<0.0001$ \\
\hline $\mathrm{O}_{3}\left(\mathrm{ug} / \mathrm{m}^{3}\right)$ & $58.8(53.7,66.5)$ & $57.9(53.5,63.1)$ & $<0.0001$ \\
\hline Gross Domestic Product (GDP, thousand Yuan) & $81.24(58.59,115.05)$ & $80.14(61.21,116.56)$ & $<0.0001$ \\
\hline Urine iodine (ug/L) & $64.2(49.8,100.9)$ & $72.1(49.8$ 100.9) & $<0.0001$ \\
\hline
\end{tabular}

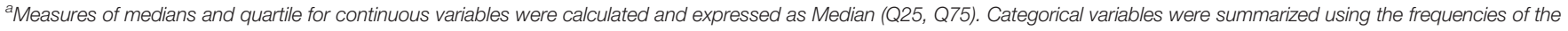
levels of the variables and corresponding proportions, and presented as $n(\%)$.

${ }^{b}$ There were 761,801 (15.5\%) missing values for medical history, including history of hypertension, diabetes and dyslipidemia, as well as treatment of hypertension and diabetes.

${ }^{c}$ There were 7,304 (0.1\%), 7,445 (0.2\%), 232 (0.005\%) missing values for systolic pressure, diastolic pressure, and total cholesterol, respectively.

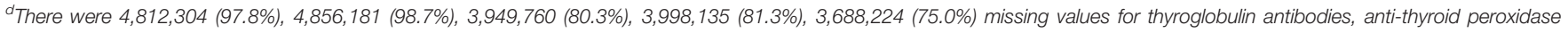
antibody, total triiodothyronine (T3), total tetraiodothyronine (T4), and thyroid stimulating hormone (TSH), respectively.

guideline $\left(<25 \mu \mathrm{g} / \mathrm{m}^{3}\right.$ for $\mathrm{NO}_{2}, 10 \mu \mathrm{g} / \mathrm{m}^{3}$ for $\mathrm{SO}_{2}, 700 \mu \mathrm{g} / \mathrm{m}^{3}$ for $\mathrm{CO}$, and $60 \mu \mathrm{g} / \mathrm{m}^{3}$ for $\mathrm{O}_{3}$ ) were included. The current WHO annual mean limit value for $\mathrm{NO}_{2}, \mathrm{SO}_{2}, \mathrm{CO}$, and $\mathrm{O}_{3}$ were $40 \mu \mathrm{g} / \mathrm{m}^{3}$, $20 \mu \mathrm{g} / \mathrm{m}^{3}, 4,000 \mu \mathrm{g} / \mathrm{m}^{3}, 100 \mu \mathrm{g} / \mathrm{m}^{3}$, respectively. These findings suggest that significant adverse health effects occur at concentrations well below accepted limits, supporting the idea that significant health benefits can be achieved by moving towards that guideline, while also adding new evidence concerning the important human organ.

The significant associations between air pollutants exposure and TNs remained stable in this study, even after thoroughly adjusting well-known confounders adhering to previous studies $(9,21)$. Those findings were complementarily consistent with existing sets of evidence focused on the association between air 
TABLE 2 | Results of logistic regression for the association between exposure to air pollution and thyroid nodules ${ }^{2}$.

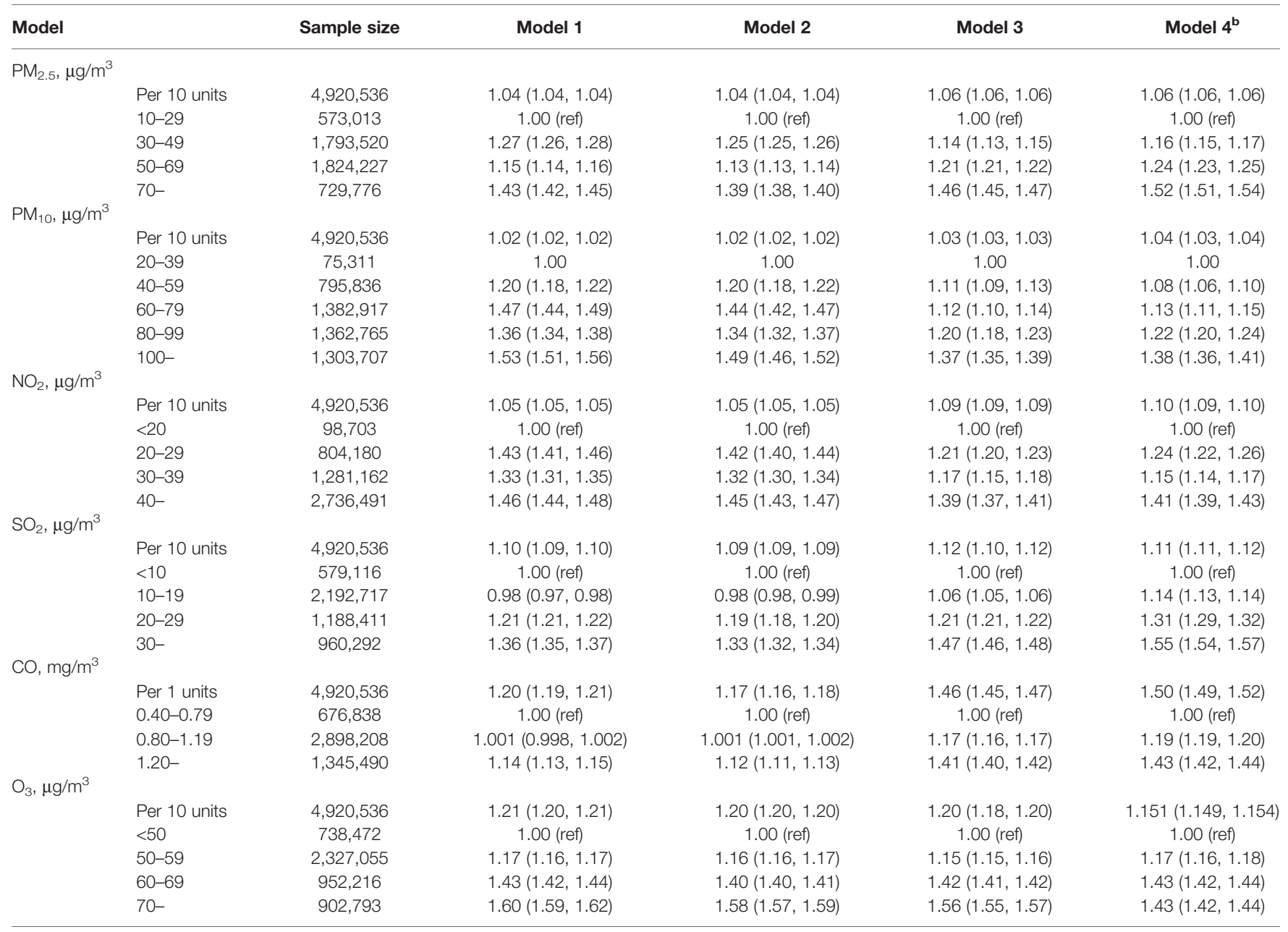

Data are OR $(95 \% \mathrm{Cl})$, unless indicated otherwise. ORs are presented for the following increments: $10 \mu \mathrm{g} / \mathrm{m}^{3}$ for $P M_{2.5}, \mathrm{PM}_{10}, \mathrm{NO}_{2}, \mathrm{SO}_{2}$, and $\mathrm{O}_{3}$, and $1 \mathrm{mg} / \mathrm{m}^{3}$ for $\mathrm{CO}$. OR, Odds ratio. ${ }^{a}$ Model 1 included only age, and sex. Model 2 added individual level variables: fasting blood glucose, body mass index, triglyceride, low density lipoprotein, and high density lipoprotein. Model 3 added city-level variables including Gross Domestic Product, and $\mathrm{O}_{3}$ concentration (except for $\mathrm{O}_{3}$ itself). Model 4 added province-level variables including average urine iodine level, average years of education and average smoking rate.

${ }^{b} \mathrm{P}$-values for trend in Model 1 to Model 4 were all less than 0.05

pollutants and thyroid dysfunction (6-9). The potential mechanisms explaining the effect of outdoor air pollutants on TNs risk are still unclear. Several signaling pathways may be involved. First, the outdoor air pollutants exposure may cause oxidative stress in the body, which has been described as an endogenous factor contributing to the thyroid hyperplasia (22). Second, exposure to particulate matters shapes DNA methylation through the lifespan (23), which may also be a potential mechanism for TNs pathogenesis. In addition, other pathways such as systemic inflammation and insulin resistance might also be among potential mechanisms $(24,25)$.

Furthermore, it was found that the association of air pollutants was ameliorated with TSH adjustment. TSH has been proposed to promote growth in size of thyroid cells (26). In this study, the TSH levels were relatively lower in the TNs group, which might be due to its ability to maintain TSH levels at a lower normal range by autonomous hyperfunctioning (27). Thyroid antibodies might also contribute to the growth and progression of $\mathrm{TN}$ (28). In this study, most of the ORs turned to be nonsignificant in anti-TG(+) and anti-TPO(+) group except for $\mathrm{CO}$ and $\mathrm{O}_{3}$. One possible reason was that the effects of antiTG and anti-TPO on TNs progression were too high that the effect of air pollutants was masked. Another possible reason was that the anti-TG(+) and anti-TPO(+) patients have more sophisticated immune systems compared to the anti-TG(-) and anti-TPO(-) groups, which may have a stronger inflammatory response when their immune systems are triggered, and the moderate inflammation may play some role in defending air pollutant effect. Some studies also reported that high anti-TPO titers appear to protect against differentiated thyroid cancer in patients with Hashimoto's thyroiditis (29).

Females have been reported to be more vulnerable to air pollution $\left(\mathrm{PM}_{10}, \mathrm{SO}_{2}, \mathrm{NO}_{2}\right.$, and $\left.\mathrm{O}_{3}\right)$, and to have a higher air pollution-related mortality than males in a few studies (30). However, this study with a large sample size demonstrated that ORs for each pollutant with TNs were consistently lower in 


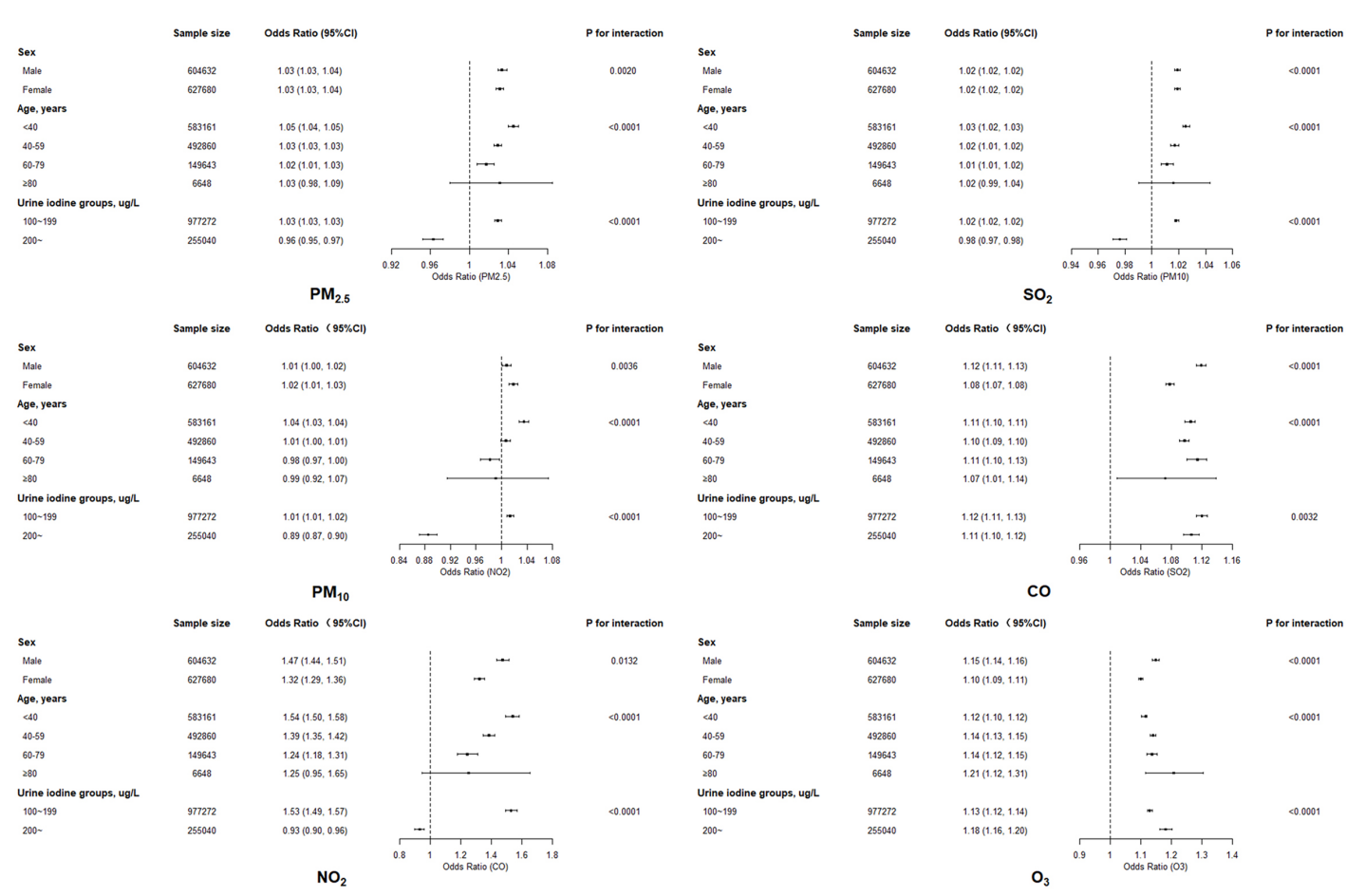

FIGURE 2 | The association between exposure to six air pollutants and thyroid nodules by sex, age, and urine iodine levels.

TABLE 3 | Sensitivity analyses results ${ }^{a}$.

\begin{tabular}{|c|c|c|c|c|c|c|c|}
\hline & \multicolumn{7}{|c|}{ Odds ratio } \\
\hline & Sample size & $\begin{array}{l}\text { PM2.5 (ug/m³, } \\
\text { Per } 10 \text { units) }\end{array}$ & $\begin{array}{l}\text { PM10 (ug/m³, } \\
\text { Per } 10 \text { units) }\end{array}$ & $\begin{array}{l}\text { NO2 (ug/m } \mathrm{m}^{3} \\
\text { Per } 10 \text { units) }\end{array}$ & $\begin{array}{l}\text { SO2 (ug/m }{ }^{3} \\
\text { Per } 10 \text { units) }\end{array}$ & $\begin{array}{l}\mathrm{CO} \text { (mg/m }{ }^{3} \\
\text { Per } 1 \text { units) }\end{array}$ & $\begin{array}{l}\text { O3 (ug/m³ } \\
\text { Per } 10 \text { units) }\end{array}$ \\
\hline $\begin{array}{l}\text { A: Adjust the potential effect } \\
\text { of city heterogeneity }\end{array}$ & $4,920,536$ & $1.04(1.01,1.08)$ & $1.02(1.01,1.04)$ & $1.12(1.05,1.18)$ & $1.09(1.05,1.14)$ & $1.42(1.20,1.68)$ & $1.17(1.10,1.26)$ \\
\hline $\begin{array}{l}\text { B1: Adjusting for thyroid } \\
\text { stimulating hormone }\end{array}$ & $1,232,312$ & $1.03(1.03,1.03)$ & $1.02(1.02,1.02)$ & $1.01(1.01,1.02)$ & $1.09(1.09,1.10)$ & $1.40(1.37,1.42)$ & $1.13(1.12,1.13)$ \\
\hline $\begin{array}{l}\text { B2: Further adjusting for } \\
\text { temperature }\end{array}$ & $1,232,312$ & $1.01(1.01,1.02)$ & $1.01(1.00,1.01)$ & $0.99(0.99,1.00)$ & $1.08(1.08,1.09)$ & $1.23(1.20,1.26)$ & $1.12(1.10,1.12)$ \\
\hline $\begin{array}{l}\text { B3: Further adjusting for } \Pi \text { T3 } \\
\& \pi 4\end{array}$ & 83,7474 & $1.05(1.05,1.05)$ & $1.02(1.02,1.02)$ & $1.05(1.05,1.06)$ & $1.09(1.09,1.10)$ & $1.34(1.32,1.37)$ & $1.10(1.09,1.10)$ \\
\hline
\end{tabular}

${ }^{a}$ Each model was basically adjusted for age, sex, fasting blood glucose, body mass index, triglyceride, low density lipoprotein, high density lipoprotein, Urine iodine, O3, Gross Domestic Product (GDP), education index and average smoking rate. P-values for trend in all models were all less than 0.05.

participants who were women and/or elderly, which contradicts the sex-specific effect of air pollutant on other outcomes including thyroid function indexes and mortality. Clear reasons for the sex-specific effects of air pollution are not well known. One explanation could be due to the fact that women and the elderly were already more likely to suffer from TNs (5), while the group with higher risk profiles is always apt to detect a relatively lower OR resulting from some loss of statistical power (20). Another reason is that the estrogen and progesterone might also contribute to the sex disparity (31), which needs further study to confirm. Another interesting discovery in this study was that lower urine iodine level has higher ORs for each pollutant. The relatively low risk profile in the group with appropriate urine iodine level should also be one reason. Besides, cigarette smoking could inhibit iodine transport, iodine organification, and increase iodide efflux, which may promote the occurrence of thyroid nodules (32). It is reasonable to postulate that the effect of air pollutant on iodine metabolism is ameliorated in the excess iodine region.

Air pollutants especially particulate matter in outdoor air pollution has become one of the biggest threats to the health of the Chinese people. Although appreciable reductions of the annual average concentrations for most of pollutants were observed from 2013 (33), the current concentrations for fine particulate, $\mathrm{NO}_{2}$ and $\mathrm{SO}_{2}$ were still higher than the WHO recommendations. The newly-found associations together with 


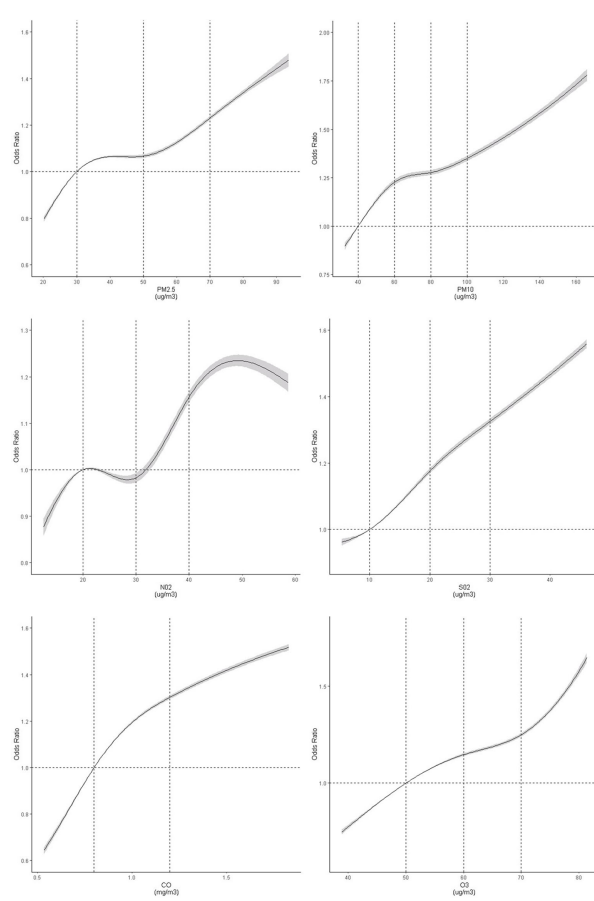

FIGURE 3 | Dose-response association between air pollutants and risk of thyroid nodules. Restricted cubic spline was fitted for each air pollutant concentrations and thyroid nodules, with selected knots and reference for each air pollutants $\left(\mathrm{PM}_{2.5}: 30\right.$ [Ref], 50, $70 \mathrm{ug} / \mathrm{m}^{3} ; \mathrm{PM}_{10}: 40$ [Ref], 60, 80, $100 \mathrm{ug} / \mathrm{m}^{3}$; $\mathrm{NO}_{2}$ : [20], 30, $40 \mathrm{ug} / \mathrm{m}^{3} ; \mathrm{SO}_{2}: 10$ [Ref], 20, $30 \mathrm{ug} / \mathrm{m}^{3} ; \mathrm{CO}: 0.8\left[\operatorname{Ref}, 1.2 \mathrm{mg} / \mathrm{m}^{3}\right.$; $\mathrm{O}_{3}: 40\left[\right.$ Ref], 50, $60,70 \mathrm{ug} / \mathrm{m}^{3}$ ). The model was adjusted for age, sex, fasting blood glucose, body mass index, triglyceride, low density lipoprotein, high density lipoprotein, urine iodine, $\mathrm{O}_{3}$, Gross Domestic Product, education index, and average smoking rate. The graph indicated a non-linear association between air pollutant concentrations and thyroid nodules (test for spline model: $P<0.0001)$. $P$-values for nonlinear tests were $0.0029,<0.0001,0.0144$, $0.9585,0.0118$ and 0.21473 for six pollutants, respectively.

previous researches (6-9), have at least two implications. First, the new evidence was added for the adverse health effect of air pollution in the perspective of the important endocrine organ, with connecting major air pollutants with the highly prevalent disease. Second, it is safely assumed that plenty of TNs patients would unsurprisingly appear in next decades without expeditious and effective measures to control air pollutants. The findings provide evidence to implement effective air-quality improvement strategies and management plans, addressing an arduous task in managing the challenges of environmental pollution in China and other countries facing similar air pollution issues.

Nonetheless, the study has several limitations. First, assigning each participant the average concentration of air pollutants over the city in which he or she visited the health screening center was a rough estimate, but the corresponding variation is expected to be minimal. Second, whether TNs were benign or cancerous were not diagnosed by the general practice in health screening centers, which has hindered further exploration of the relationship between air pollutants and the different types of TNs (21). Lastly, causal inference was limited by the observational study design, although the reverse effect of TNs causing air pollutants changes is scarcely possible.

\section{CONCLUSIONS}

In conclusion, with an unprecedented large sample size and measures of multiple air pollutants across a wide geographic area, the findings of this study show that exposure to six air pollutants is significantly associated with an increased risk of thyroids nodules, even at concentration ranges well below the annual mean limit value suggested by the WHO. Further longitudinal studies are needed to confirm these findings, and to clarify potential mechanisms that might be responsible for the association between air pollutants exposure and TNs.

\section{DATA AVAILABILITY STATEMENT}

The raw data supporting the conclusions of this article will be made available by the authors, without undue reservation.

\section{ETHICS STATEMENT}

The studies involving human participants were reviewed and approved by the Ethical Committee of the Health Science Center of Peking University. The patients/participants provided their written informed consent to participate in this study.

\section{AUTHOR CONTRIBUTIONS}

Conception: SW, YFS, and YN. Design: SW, YFS, and YN. Administrative support: YN and LL. Provision of study material or patients: CJ. Collection and assembly of data: YZ, WQ, SW, and CJ. Data analysis and interpretation: YZ, KW, SW, YFS, YQS, PJ, YN, and LL. Manuscript writing: YZ, KW, SW, and YFS. All authors contributed to the article and approved the submitted version.

\section{FUNDING}

This work was funded by the National Natural Science Foundation of China (81922016, 91846303, and 81502884) and the National Key R\&D program (2020YFC2003400). The funders had no role in the study design; collection, analysis, and interpretation of data; writing of the report; or decision to submit the article for publication.

\section{SUPPLEMENTARY MATERIAL}

The Supplementary Material for this article can be found online at: https://www.frontiersin.org/articles/10.3389/fendo.2021. 753607/full\#supplementary-material 


\section{REFERENCES}

1. Haugen BR, Alexander EK, Bible KC, Doherty GM, Mandel SJ, Nikiforov YE, et al. 2015 American Thyroid Association Management Guidelines for Adult Patients With Thyroid Nodules and Differentiated Thyroid Cancer: The American Thyroid Association Guidelines Task Force on Thyroid Nodules and Differentiated Thyroid Cancer. Thyroid (2016) 26(1):1-133. doi: 10.1089/ thy.2015.0020

2. Tufano RP, Noureldine SI, Angelos P. Incidental Thyroid Nodules and Thyroid Cancer: Considerations Before Determining Management. JAMA Otolaryngol Head Neck Surg (2015) 141(6):566-72. doi: 10.1001/jamaoto. 2015.0647

3. Panagiotou G, Komninou D, Anagnostis P, Linardos G, Karoglou E, Somali M, et al. Association Between Lifestyle and Anthropometric Parameters and Thyroid Nodule Features. Endocrine (2017) 56(3):560-7. doi: 10.1007/ s12020-017-1285-6

4. Kim ES, Lim DJ, Baek KH, Lee JM, Kim MK, Kwon HS, et al. Thyroglobulin Antibody is Associated With Increased Cancer Risk in Thyroid Nodules. Thyroid (2010) 20(8):885-91. doi: 10.1089/thy.2009.0384

5. Knudsen N, Laurberg P, Perrild H, Bulow I, Ovesen L, Jorgensen T. Risk Factors for Goiter and Thyroid Nodules. Thyroid (2002) 12(10):879-88. doi: 10.1089/105072502761016502

6. Wang X, Liu C, Zhang M, Han Y, Aase H, Villanger GD, et al. Evaluation of Maternal Exposure to PM2.5 and Its Components on Maternal and Neonatal Thyroid Function and Birth Weight: A Cohort Study. Thyroid (2019) 29 (8):1147-57. doi: 10.1089/thy.2018.0780

7. Howe CG, Eckel SP, Habre R, Girguis MS, Gao L, Lurmann FW, et al. Association of Prenatal Exposure to Ambient and Traffic-Related Air Pollution With Newborn Thyroid Function: Findings From the Children's Health Study. JAMA Netw Open (2018) 1(5):e182172. doi: 10.1001/ jamanetworkopen.2018.2172

8. Zhao Y, Cao Z, Li H, Su X, Yang Y, Liu C, et al. Air Pollution Exposure in Association With Maternal Thyroid Function During Early Pregnancy. J Hazard Mater (2019) 367:188-93. doi: 10.1016/j.jhazmat.2018.12.078

9. Janssen BG, Saenen ND, Roels HA, Madhloum N, Gyselaers W, Lefebvre W, et al. Fetal Thyroid Function, Birth Weight, and in Utero Exposure to Fine Particle Air Pollution: A Birth Cohort Study. Environ Health Perspect (2017) 125(4):699-705. doi: 10.1289/ehp508

10. Alink GM, Brouwer A, Heussen GA. Effects of Outdoor and Indoor Airborne Particulate Matter on Thyroid Hormone and Vitamin A Metabolism. Toxicol Lett (1994) 72(1-3):73-81. doi: 10.1016/0378-4274(94)90012-4

11. Welker MJ, Orlov D. Thyroid Nodules. Am Fam Physician (2003) 67 (3):559-66.

12. Chen R, Yin P, Meng X, Liu C, Wang L, Xu X, et al. Fine Particulate Air Pollution and Daily Mortality. A Nationwide Analysis in 272 Chinese Cities. Am J Respir Crit Care Med (2017) 196(1):73-81. doi: 10.1164/rccm.201609$1862 \mathrm{OC}$

13. Yin P, Chen R, Wang L, Meng X, Liu C, Niu Y, et al. Ambient Ozone Pollution and Daily Mortality: A Nationwide Study in 272 Chinese Cities. Environ Health Perspect (2017) 125(11):117006. doi: 10.1289/ehp1849

14. Chen Y, Wang C, Shang H, Yang K, Norris SL. Clinical Practice Guidelines in China. Bmj (2018) 360:j5158. doi: 10.1136/bmj.j5158

15. Wang M, Luo X, Xu S, Liu W, Ding F, Zhang X, et al. Trends in Smoking Prevalence and Implication for Chronic Diseases in China: Serial National Cross-Sectional Surveys From 2003 to 2013. Lancet Respir Med (2019) 7(1):11. doi: 10.1016/S2213-2600(18)30432-6

16. Zhao L, Teng D, Shi X, Li Y, Ba J, Chen B, et al. The Effect of Increased Iodine Intake on Serum Thyrotropin: A Cross-Sectional, Chinese Nationwide Study. Thyroid (2020) 30(12):1810-9. doi: 10.1089/thy.2019.0842

17. Chen Z, Xu W, Huang Y, Jin X, Deng J, Zhu S, et al. Associations of Noniodized Salt and Thyroid Nodule Among the Chinese Population: A Large Cross-Sectional Study. Am J Clin Nutr (2013) 98(3):684-92. doi: 10.3945/ajcn.112.054353

18. WHO Regional Office for Europe. WHO Air Quality Guidelines for Particulate Matter, Ozone, Nitrogen Dioxide and Sulfur Dioxide. Global Update 2005. Summary of Risk Assessment. (2005).

19. Shurong Z, Fan W, Changyi G, Jun S, Cuihua H, Zhenni Z, et al. Iodine Nutrition and the Prevalence of Thyroid Disease After Salt Iodization:
A Cross-Sectional Survey in Shanghai, a Coastal Area in China. PloS One (2012) 7(7):e40718. doi: 10.1371/journal.pone.0040718

20. Beelen R, Raaschou-Nielsen O, Stafoggia M, Andersen ZJ, Weinmayr G, Hoffmann B, et al. Effects of Long-Term Exposure to Air Pollution on Natural-Cause Mortality: An Analysis of 22 European Cohorts Within the Multicentre ESCAPE Project. Lancet (2014) 383(9919):785-95. doi: 10.1016/ s0140-6736(13)62158-3

21. Li L, Ying Y, Zhang C, Wang W, Li Y, Feng Y, et al. Bisphenol A Exposure and Risk of Thyroid Nodules in Chinese Women: A Case-Control Study. Environ Int (2019) 126:321-8. doi: 10.1016/j.envint.2019.02.026

22. Lim CC, Thurston GD. Air Pollution, Oxidative Stress, and Diabetes: A Life Course Epidemiologic Perspective. Curr Diabetes Rep (2019) 19(8):58. doi: 10.1007/s11892-019-1181-y

23. Ferrari L, Carugno M, Bollati V. Particulate Matter Exposure Shapes DNA Methylation Through the Lifespan. Clin Epigenet (2019) 11(1):129. doi: $10.1186 /$ s13148-019-0726-x

24. Gaio V, Roquette R, Dias CM, Nunes B. Ambient Air Pollution and Lipid Profile: Systematic Review and Meta-Analysis. Environ Pollut (2019) 254(Pt B):113036. doi: 10.1016/j.envpol.2019.113036

25. Bowe B, Xie Y, Li T, Yan Y, Xian H, Al-Aly Z. The 2016 Global and National Burden of Diabetes Mellitus Attributable to PM2.5 Air Pollution. Lancet Planet Health (2018) 2(7):e301-e12. doi: 10.1016/S2542-5196(18)30140-2

26. Kimura T, Dumont JE, Fusco A, Golstein J. Insulin and TSH Promote Growth in Size of PC Cl3 Rat Thyroid Cells, Possibly via a Pathway Different From DNA Synthesis: Comparison With FRTL-5 Cells. Eur J Endocrinol (1999) 140 (1):94-103. doi: 10.1530/eje.0.1400094

27. Shin J, Kim MH, Yoon KH, Kang MI, Cha BY, Lim DJ. Relationship Between Metabolic Syndrome and Thyroid Nodules in Healthy Koreans. Korean J Intern Med (2016) 31(1):98-105. doi: 10.3904/kjim.2016.31.1.98

28. Xu W, Huo L, Chen Z, Huang Y, Jin X, Deng J, et al. The Relationship of TPOAb and TGAb With Risk of Thyroid Nodules: A Large Epidemiological Study. Int J Environ Res Public Health (2017) 14(7):723. doi: 10.3390/ ijerph14070723

29. Paparodis R, Imam S, Todorova-Koteva K, Staii A, Jaume JC. Hashimoto's Thyroiditis Pathology and Risk for Thyroid Cancer. Thyroid (2014) 24 (7):1107-14. doi: 10.1089/thy.2013.0588

30. Zanobetti A, Schwartz J. Race, Gender, and Social Status as Modifiers of the Effects of PM10 on Mortality. J Occup Environ Med (2000) 42(5):469-74. doi: 10.1097/00043764-200005000-00002

31. Wang K, Yang Y, Wu Y, Chen J, Zhang D, Liu C. The Association of Menstrual and Reproductive Factors With Thyroid Nodules in Chinese Women Older Than 40 Years of Age. Endocrine (2015) 48(2):603-14. doi: 10.1007/s12020-014-0342-7

32. Hood A, Liu YP, Gattone VH2nd, Klaassen CD. Sensitivity of Thyroid Gland Growth to Thyroid Stimulating Hormone (TSH) in Rats Treated With Antithyroid Drugs. Toxicol Sci (1999) 49(2):263-71. doi: 10.1093/toxsci/49.2.263

33. Jing H, Pan X, Guo X, Li G. Health Impact of China's Air Pollution Prevention and Control Action Plan: An Analysis of National Air Quality Monitoring and Mortality Data. Lancet Planet Health (2018) 2(7):e313-23. doi: 10.1016/ S2542-5196(18)30141-4

Conflict of Interest: The authors declare that the research was conducted in the absence of any commercial or financial relationships that could be construed as a potential conflict of interest.

Publisher's Note: All claims expressed in this article are solely those of the authors and do not necessarily represent those of their affiliated organizations, or those of the publisher, the editors and the reviewers. Any product that may be evaluated in this article, or claim that may be made by its manufacturer, is not guaranteed or endorsed by the publisher.

Copyright $(2021$ Zhang, Wang, Qin, Jin, Song, Jia, Wang, Song, Ning and Li. This is an open-access article distributed under the terms of the Creative Commons Attribution License (CC BY). The use, distribution or reproduction in other forums is permitted, provided the original author(s) and the copyright owner(s) are credited and that the original publication in this journal is cited, in accordance with accepted academic practice. No use, distribution or reproduction is permitted which does not comply with these terms. 